\title{
DNA analysis in Finnish patients with hereditary neuropathy with liability to pressure palsies (HNPP)
}

Kaisa Silander, Päivi Halonen, Rolf Sara, Hannu Kalimo, Björn Falck, Marja-Liisa Savontaus

\begin{abstract}
Hereditary neuropathy with liability to pressure palsies (HNPP) is a dominantly inherited disorder that presents as recurrent mononeuropathies precipitated by apparently trivial traumas. The presence of a deletion in $17 \mathrm{p} 11 \cdot 2$ was analysed in 13 Finnish families with HNPP. The deletion was found in all patients who were neurologically and neurophysiologically confirmed to have HNPP. In the problematic cases the detection of the gene defect is the method of choice in the diagnosis of HNPP. Analysis of DNA can also be used to detect clinically unaffected family members.
\end{abstract}

$(F$ Neurol Neurosurg Psychiatry 1994;57:1260-1262)

Department of Medical Genetics, University and University Central Hospital of Turku, 20520 Turku, Finland K Silander

M-L Savontaus

Department of Clinical

Neurophysiology,

University Central

Hospital of Turku,

20520 Turku, Finland

P Halonen

B Falck

Centre for

Biotechnology, 20520

Turku, Finland

R Sara

Department of Pathology, University of Turku, 20520 Turku, Finland H Kalimo

Department of Biology, University of Turku, 20500 Turku, Finland

M-L Savontaus

Correspondence to:

Dr M-L Savontaus,

Department of Medical

Department of Medic

Genetics, Institute of

Biomedicine, University and

of Turku, 20520 Turku, Finland.

Received 2 November 1993 and in final revised form 22 April 1994.

Accepted 28 April 1994 lower extremities show mild to moderate neurogenic abnormalities. Pathological changes include segmental demyelination and tomac-

Several studies ${ }^{56}$ have confirmed the autosomal dominant mode of inheritance in HNPP. Recently, Chance et $a l$ reported a large interstitial deletion in $17 \mathrm{p} 11.2$ associated with HNPP in three unrelated pedigrees. The deletion spans about $1.5 \mathrm{Mb}$ and includes all the markers previously shown to be duplicated in Charcot-Marie-Tooth dis- ease type 1A (CMT1A or HMSN 1A) ${ }^{89}$ The candidate gene for CMT1A, PMP22, encoding a peripheral myelin protein map within the area of duplication. ${ }^{8}$ Furthermore, the breakpoints in HNPP and in CMT1A map to the same interval in $17 \mathrm{p} 11 \cdot 2$, suggesting that these two disorders may be due to reciprocal products of unequal crossing over.

Here we report the results of DNA analysis in 13 Finnish families with clinical diagnosis of HNPP.

\section{Family material}

Our family material consisted of 13 families with HNPP (fig 1). Fifty one family members had been neurologically and neurophysiologically examined. Forty three of them had clinical evidence of mononeuropathies and many of them had a history of recurrent neuropathies. A minor trauma or compressive labour often preceded nerve lesions. Furthermore, most of them also had reduced tendon reflexes. None of them had systemic diseases; nor was there any evidence of drug or toxic exposure. Reduced nerve conduction velocities were found both in affected and non-affected nerves. The remaining eight family members showed no clinical or neurophysiological evidence of HNPP.

Blood samples were obtained from 33 out of 43 patients who were clinically and neurophysiologically shown to have HNPP, and from two subjects from family 4 who were clinically and neurophysiologically unaffected. Blood samples were also obtained from 18 family members who were not clinically or neurophysiologically examined and from five patients who were clinically affected but not neurophysiologically studied. A nerve biopsy was obtained from two patients. ulous swellings. ${ }^{4}$

\section{Methods}

Genomic DNA was isolated by a standard phenol-chloroform extraction procedure. The DNA was digested with the restriction enzymes MspI or EcoRI according to the manufacturer's conditions, separated by 1.0 or $1.2 \%$ agarose gel electrophoresis, respectively, and transferred to a nylon membrane. The filters were hybridised with the ${ }^{32} \mathrm{P}$ 
1

3

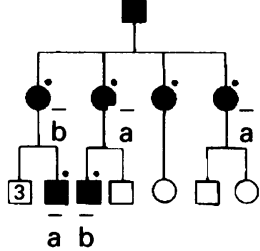

2

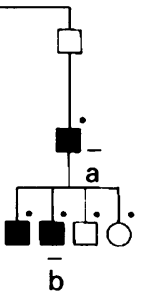

4

।
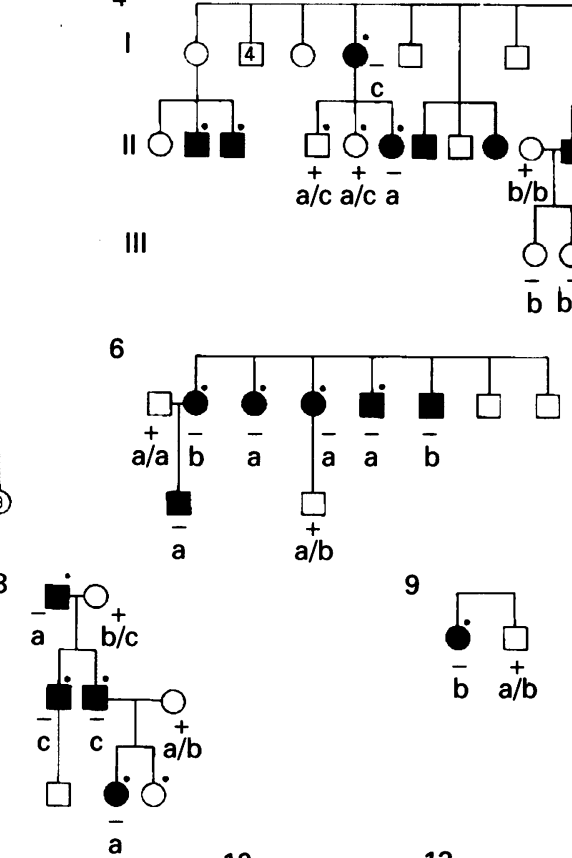

11

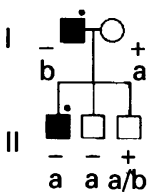

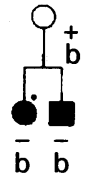

12

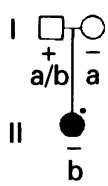

13

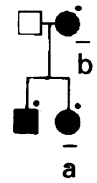

Figure 1 Pedigrees of 13 families. Open symbols, unaffected; filled symbols, affected with HNPP. Neurologically and neurophysiologically examined people are indicated with

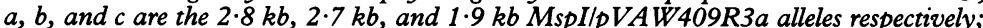
- and + indicate one and two copies of the $17 p 11 \cdot 2$ region, respectively, determined by band density and by comparing with control probe SF85.

labelled probe pVAW409R3a (D17S122) and the reference probe SF85 (D21S46), both provided by Dr Christine van Broeckhoven (University of Antwerp, Antwerpen, Belgium). Probe pVAW409R3a detects on MspI digestion alleles of $2.8 \mathrm{~kb}, 2 \cdot 7 \mathrm{~kb}$, and $1.9 \mathrm{~kb}$, and on EcoRI digestion a constant band of $2.0 \mathrm{~kb}$. The reference probe SF85 detects on MspI digestion one constant band of about $4.5 \mathrm{~kb}$ and on EcoRI digestion one constant band of about $1.4 \mathrm{~kb}$.

Deletion analysis in patients with HNPP and controls by measurement of hybridisation signals with pVAW409R3a and the reference probe SF85

\begin{tabular}{|c|c|c|c|c|}
\hline \multirow[b]{2}{*}{ Film No } & \multicolumn{2}{|l|}{ Controls } & \multicolumn{2}{|l|}{ Patients } \\
\hline & Median (range) & $N$ & Median (range) & $N$ \\
\hline $\begin{array}{l}1 \\
2 \\
3 \\
4 \\
5 \\
6\end{array}$ & $\begin{array}{l}2.79(2.94-2 \cdot 15) \\
1.46(1.90-1.28) \\
1.84(2.17-1.43) \\
6.39(7.85-5.74) \\
1.93(2.94-1.26) \\
1.87(2.49-1.30)\end{array}$ & $\begin{array}{r}6 \\
9 \\
10 \\
6 \\
3 \\
9\end{array}$ & $\begin{array}{l}1.33(1.72-1.22) \\
0.73(0.85-0.52) \\
0.91(1.08-0.79) \\
2.93(3.85-1.82) \\
0.74(1.33-0.65) \\
0.90(1.19-0.61)\end{array}$ & $\begin{array}{r}10 \\
8 \\
9 \\
5 \\
6 \\
8\end{array}$ \\
\hline
\end{tabular}

Gene copy number was estimated by visual assessment of polymorphic bands on autoradiograms and corroborated by measurement of band density and comparison with control marker (SF85) using a densitometric analysis (MCID, Image Analysis System).

Nerve biopsies were processed for semithin epon section, teasing, and electron microscopy according to our modification of the previously published method. ${ }^{10}$

\section{Results}

All 33 patients from 13 families (fig 1) who were clinically and neurophysiologically (two of them also neuropathologically) confirmed to have HNPP harboured the deletion in $17 \mathrm{p} 11 \cdot 2$. The deletion was also detected in the five patients who were clinically affected but not neurophysiologically examined. In all affected patients the presence of the deletion was determined by comparing the relative intensity of the $17 \mathrm{pl1} .2$ band with the constant band of the reference probe SF85 on EcoRI digestion (fig 2). The intensity differences noticed by visual inspection were confirmed by densitometric analysis. Due to the differences in labelling and hybridisation in each film, the calculated ratio of the signals for pVAW409R3a and SF85 differed significantly between affected and non-affected patients. Thus only the ratios within the same film could be compared. The ratios for the patients were about half of the ratios for the control patients in each film (table).

In all families the segregation of pVAW409R3a/MspI alleles was also followed. Nine families were informative and a loss of a pVAW409R3a allele was found. For example, in family 8 (fig 2) the two affected males (II-1 and II-2) are hemizygous for the pVAW409R3a locus. They have inherited their only $1.9 \mathrm{~kb}$ allele (c) from their healthy mother and no pVAW409R3a allele from their affected father. Similarly III-2 has inherited the $2.8 \mathrm{~kb}$ allele (a) from her healthy mother and no allele from the affected father. The deletion was also detected in four subjectively healthy subjects (III-1 in family 4, II-2 in family 7 , II-2 in family 10 , and I-2 in family 12) who had no history of mononeuropathies but who have not been clinically or neurophysiologically examined.

The transmission of the deletion (also male to male) through three generations was seen in two families and in eight families deletion was found in two generations confirming the autosomal dominant inheritance of HNPP.

\section{Discussion}

Recently, the HNPP locus was assigned to chromosome $17 \mathrm{p} 11.2$ and an interstitial deletion was shown to be associated with the disorder in three pedigrees. ${ }^{7}$ Similarly, Mariman et $a l^{11}$ have detected a loss of heterozygosity of the D17S122 (pVAW409R3) locus in one large HNPP family. Here we report the presence of a deletion in 13 unrelated Finnish families with HNPP. All family members, 
A

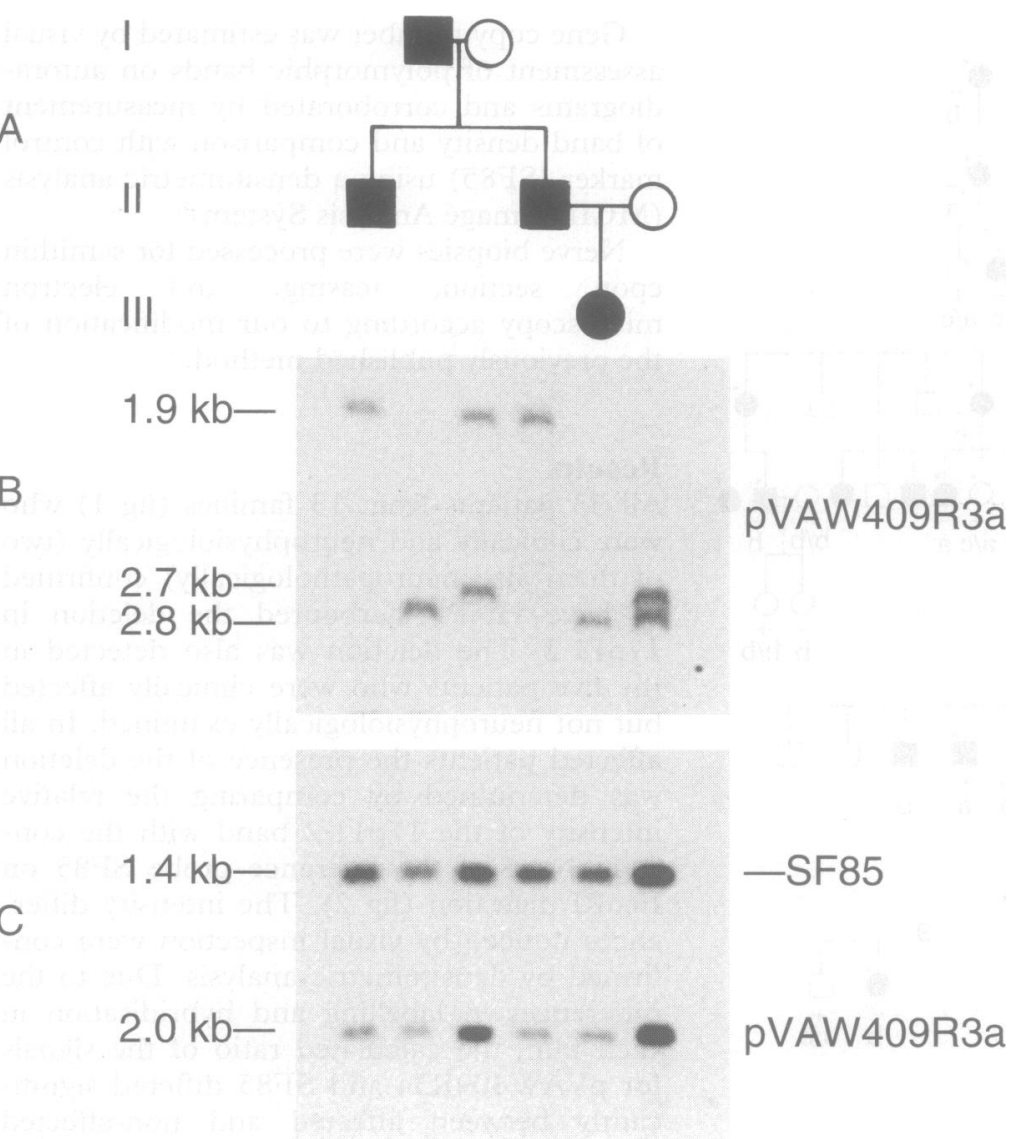

Figure 2 Inheritance of $17 p 11 \cdot 2$ markers in HNPP. (A) The pedigree of family 8 (B) and $(C)$ MspI and EcoRI digestions hybridised by $p V A W 409 R 3 a$ and control probe SF85 respectively. gle case, however, it is recommended that two $17 \mathrm{p} 11.2$ probes are used as in the diagnostic test for CMT1a, ${ }^{12}$ because the control and patient ranges for one probe may overlap (table).

Although HNPP is a benign disorder, we believe that the gene defect should be identified in clinically unaffected family members at an early age. If the patients are aware of their liability to develop pressure neuropathies they may avoid situations where their nerves may become exposed to chronic pressure either at work or at leisure time.

So far there have been no specific laboratory tests for HNPP. Diagnosis of HNPP has relied on medical history, clinical, neurophysiological, and neuropathological findings, and on heredity. In most of our patients the tentative diagnosis of HNPP was made when a patient with mononeuropathy showed generalised abnormalities of nerve conduction. If the patient had the typical clinical presentation and neurophysiological findings the diagnosis of probable HNPP was made. Subsequently the family members were studied. If another family member showed the typical neurophysiological findings the diagnosis was definite HNPP. Nerve biopsy was done on only two patients. We believe that nerve biopsy, which may cause considerable inconvenience to the patient, is not to be recommended in this benign disorder, all the more now with the DNA diagnostics available. The accuracy of diagnosis based on medical history, heredity, and neurophysiological findings is shown by our study: all the patients diagnosed as having HNPP harboured the $17 \mathrm{p} 11 \cdot 2$ deletion.

who were confirmed to have HNPP harbour the deletion whereas neurologically unaffected family members had two copies of the pVAW409R3 locus. The deletion was also detected in four subjectively healthy subjects aged $3,15,25$, and 46 years, with no history of illness. Unfortunately, these four subjects have not been investigated clinically or neurophysiologically to assess whether the deletion may appear in truly asymptomatic form.

The detection of the deletion in the same chromosomal region in all reported HNPP patients indicates that HNPP is due to the deletion of pVAW409R3 in most if not all of the cases. The possible allelic heterogeneity remains to be shown by further studies, however, with markers of the critical region of $17 \mathrm{p} 11 \cdot 2$.

In most patients with HNPP there are usually no problems with differential diagnosis, but in patients with no evident heredity, establishing a firm diagnosis may sometimes be difficult. Also, in some patients there may be problems in differentiating HNPP from other polyneuropathies, especially HMSN1. In these patients the value of the DNA analysis is obvious. In our data a loss of a pVAW409R3a allele was easily seen on analysing several members of nine informative families out of 13 studied. In these cases the diagnosis of HNPP is conclusive. When DNA analysis is used diagnostically in a sin-
1 Windebank AJ. Inherited recurrent focal neuropathies. In: Dyck PJ, Thomas PK, Griffin JW, Low PA, Poduslo JF, eds. Peripheral neuropathy. 3rd ed. Philadelphia: WB Saunders, 1992:1137-48

2 Verhagen VIM, Gabreels-Festen AAWM, van Wensen PJM, et al. Hereditary neuropathy with liability to presmorphological study. I Neurol Sci 1993;116:176-84

3 Behse F, Buchthal F, Carsen F, Knappels G. Hereditary neuropathy with liability to pressure palsies: electrophysiological and histopathological aspects. Brain 1972; 95:777-86.

4 Sellman MS, Mayer RF. Conduction block in hereditary neuropathy with susceptibility to pressure palsies. neuropathy with susceptibilit a family and a survey. Brain 1972;95:235-48.

6 Staal A, De Weerdt CJ, Went LN. Hereditary compression syndrome of peripheral nerves. Neurology 1965;15: 1008-17.

7 Chance PF, Alderson MK, Leppig KA, et al. DNA deletion associated with hereditary neuropathy with liability to pressure palsies. Cell 1993;72:143-51.

8 Matsunami N, Smith B, Ballard L, et al. Peripheral myelin protein-22 gene maps in the duplication in chromosome $17 \mathrm{p} 11 \cdot 2$ associated with Charcot-Marie-Tooth $1 \mathrm{~A}$ Nature Genet 1992;1:176-9.

9 Raeymaekers P, Timmerman V, Nelis E, et al. Estimation of the size of the chromosome $17 \mathrm{p} 11.2$ duplication in Charcot-Marie-Tooth neuropathy type 1A (CMT1A). f Med Genet 1992;29:5-11.

10 Dyck PJ, Karnes J, Lais A, Lofgren EP, Stevens JC. Pathological alterations of the peripheral nervous system of humans. In: Dyck PJ, Thomas PK, Lambert EH, of humans. In: Dyck PJ, Thomas PK, Lambert EH,
Burge R, eds. Peripheral neuropathy. Philadelphia: Burge R, eds. Periph

11 Mariman ECM, Gabreels-Festen AAWM, van Beersum SEC, Jongen PJH, Ropers H-H, Gabreels FJM. Gene for hereditary neuropathy with liability to pressure palsies (HNPP) maps to chromosome 17 at or close to the locus for HMSN type 1. Hum Genet 1993;92:87-90.

12 Hensels GW, Janssen EAM, Hoogendijk JE, Valentijn LJ, Baas F, Bolhuis PA. Quantitative measurement of duplicated DNA as a diagnostic test for Charcot-MarieTooth disease type 1a. Clin Chem 1993;39:1845-9. sure palsies: a clinical, electroneurophysiological and

5 Roos D, Thygesen P. Familial recurrent polyneuropathy: 